\title{
APPLICATION OF FORECASTING METHODS IN BUSINESS
}

\author{
Laima Šečkutė, Arnoldina Pabedinskaitė \\ Vilnius Gediminas Technical University, Sauletekio 11, LT-2040 Vilnius
}

Received: 27 January, 2003

\begin{abstract}
In order to provide Lithuanian enterprises with methodical recommendations regarding forecasting, the authors of this article have analysed the advantages and limitations of various forecasting methods. The problem of the accuracy of business forecasts is considered in greater detail, and the practical ways of doing the evaluation and assurance of the accuracy of the forecasting methods under discussion are presented here. The authors of the article suggest that an integrated forecasting model should be applied as it is much more accurate than any forecasting that is provided by the mentioned methods when taken separately. This will help to reduce the cost of forecasting, which is of utmost importance to Lithuanian businesses.
\end{abstract}

Keywords: forecasting methods, sales forecasting, forecasting accuracy

Object of the research - different forecasting methods as well as their accuracy and the ways of ensuring it in practice.

Problem - a wide variety of forecasting methods and an insufficient awareness on the part of Lithuanian business people, of the necessity of forecasting. On the other hand the complexity of the forecasting methods that hinders their practical application in small and medium-sized enterprises.

Aim of the research - to prepare recommendations with respect to the selection of the forecasting methods that meet the needs of the management of small and medium-sized enterprises as well as to identify the reasons for the results and efficiency of their application.

Novelty of the research - the authors of the article introduce a number of techniques as well as a scheme of sale's forecasting, meeting the requirements of the management of small and medium-sized enterprises. Moreover, two simple measures that help to evaluate forecasting's accuracy, namely, the mean coefficient of error and the mean square deviation of an integrated forecast, are also presented.

The problem of the selection and accuracy of forecasting methods, as discussed in this article is of special significance to Lithuanian business people because of the instability of the country's corporate environment and its economic processes. Under the European Union's (EU) accession, the application of forecasting methods, to forecast the market's demand helps enterprises to reduce business risk.

A successful system for a company's planning activity enables managers to efficiently control the flow of raw materials, to effectively utilise human resources and machinery, to co-ordinate activities inside the company with the actions of suppliers, and to maintain contact with consumers with respect to market requirements.

External environment forces, such as new technologies, products, processes, and global competition, constantly dictate competition conditions in the market under which a company should operate. The main factors that determine the competitiveness of the enterprise are quality and cost. 
Successful production planning reduces stocks and increases labour productivity, reduces production time, and improves equipment and employees' utilisation, which, by responding to the fluctuations of market requirements, cuts down the cost and improves the quality and elasticity of production.

Production planning in a company usually covers several stages. At the initial stage, a highly aggregated production plan as a part of a company's activity plan is prepared. The company's activity plan, which relates and co-ordinates the activities of various offices, such as design, marketing, production and finance, provide for general production targets. This strategic plan is developed into the strategic plans of functional fields, the budgets and capacities of the offices. A production plan is a constituent part of this plan and provides for the production volumes necessary to reach the company's general goals. Production planning is most closely linked to marketing planning.

At the next stage, the main calendar production plan assessing the products demand, resources as well as aggregate capacities is prepared. The main plan is further developed into a more detailed plan of materials and capacity requirements, which reflects the amount of capacities and materials necessary for the implementation of the general plan. The last stage is the implementation of the mentioned plans in the company's shops and sales offices. At each stage of production planning, a demand for a different aggregation level is forecasted, with a whole complex of methods and techniques that are employed for this purpose.

The notion of production planning encompasses the planning of the equipment, raw materials, and human resources. By planning, we seek to ensure the implementation of production targets. Production process depends on what method of production the organisation is going to select. The selection of a method, in its turn, should take into consideration the kind of product that is going to be manufactured, the time needed for raw materials sourcing and production of components, and the type and number of operations to be carried out. Finally, the goals set for a particular production area should be considered.

Production planning can be of several kinds ranging from long-term production planning, which is necessary for strategic planning, to the preparation of a short-term working timetable or a calendar plan, which includes a week or even a day.

Calendar plans are necessary for an efficient management of production capacities. The main production plan lists all the requirements of a production system.
It shows what products are needed, how much and when. This plan is updated on a regular basis in accordance with production timing.

For the plans to be realistic, the availability of raw materials and equipment should necessarily be taken into consideration. In this respect, the process of the evaluation of the available resources and the preparation of the appropriate plan is normally repeated several times. The plans are quite frequently prepared without considering capacity limits, which may certainly mean the necessity to take into account an excessive amount of information. In order to avoid such a situation, the initial aggregate capacity planning has to be carried out.

Prior to the preparation of a calendar production plan, production volumes are set, and available resources are coordinated with production quantities. Such planning is not detailed, but it allows one to compare, at large, the general capacity requirements and the capacities available for a given period of time. This is the initial evaluation of the capacity limits. However, certain 'gaps' in specific processes of high utilisation degree may still be left. A more detailed and accurate preparation of calendar plans is enabled by a realistic main plan, which should include the total capacity planning with respect to the real capacity of all the processes.

Production planning techniques are numerous, such as "Just-in-Time" or "Materials Requirement Planning", the latter determining the way of data utilisation by thoroughly preparing the necessary components procurement schemes and securing process supply. Gant's diagrams and the critical way method $[7,13]$ offer the simplest planning model.

Capacity planning helps to prepare more accurate calendar plans of resource procurements and to coordinate the available capacities with requirements, more efficiently. For this purpose, it is necessary to determine if there are free capacities as regards the targets of the main production plan and successive actions that seek to relate the capacities with the demand for them. Insufficient capacities present an important problem, which has to be quickly solved. However, a company also has to face certain difficulties when its capacities are too large.

Sales forecasting starts by analysing the situation of a company in the present and in the future, which is determined by general internal and external conditions. The results of the situation analysis determine the company's aims and the strategy and means by which they are put into practice. 
The situation analysis should take into consideration a wide variety of internal as well as external factors. The significance and relevance of each factor depends on the specific character of a particular company and a given situation. The main factors that have to be considered are as follows:

\section{External factors:}

- Macro-environment: economic, socio-cultural, technological as well as political and legal factors.

- Microenvironment: consumers, suppliers, competitors, and other market partners.

\section{Internal factors:}

- The company's culture and philosophy;

- Financial and material resources;

- Number of employees and staff expertise;

- Size of the company, its location, type of management, organisational structure;

- Expenditure structure.

Sales forecasting requires that significant environment conditions are identified and their future changes are evaluated. Certain factors, such as legal environment factors, are identified relatively easily, because any changes in this area are regularly announced. However, there are factors, for example, changes in the conjuncture of different countries, whose forecasting is extremely complicated. It is often very difficult to predict the behaviour of consumers, competitors, and other market participants.

A company does not only adapt to the environment situation, but also seeks to influence it, especially by making use of marketing tools. Therefore, the assessment of the development of the company's environment, in the future, should take into account the impact of alternative marketing tools on the environment.

According to the results of the survey conducted among U.S. production managers [1], the information they use when preparing activity plans can be summed up in the following way (see Table 1).

Table 1 shows that more than 70 per cent of production managers regularly develop such forecasts as the companies own product's sales forecasting, direct expenditure forecasting, and direct revenue forecasting. More than 50 per cent also employ branch performance forecasting as well as the forecasts of the market share of their products and their expected profitability. In many cases, the two main elements, namely, the market share of the branch products, at the present moment, and its growth rate in the nearest future, are forecasted.

Data collected during the survey of the market situation and the analysis of this data help to predict the future development of the market and to develop a market demand forecast.

The two main methods of sale's forecasting, which are analogous to the methods of planning disaggregations and aggregations, are usually applied:

- Decomposition of a general sales forecast (a "breakdown" approach);

- Sales forecasts for individual items are developed and then combined to arrive at a general sales forecast (the "bottom-up" method, a "build-up" approach)

The "breakdown" approach includes the division of aggregate forecast evaluations into principal elements, i.e. disaggregation. Thus, in accordance with this method, the sales of a product on the country's scale may be divided into regions. "Survey of Buying Power", issued annually by the magazine Sales Marketing Management, is widely used in the U.S. as a source of information on the "breakdown" forecasting method. The pecuniary expression of the forecast developed with the help of this technique is also possible on the basis of the volume of the sales of different products in the retail market.

Let us suppose that 7,39 per cent of the population of a country lives in the capital. The city accounts for 8,45 per cent of the country's income and for 6,95 per cent of all the country's sales in the retail market. The producer can make use of the mentioned factors, which are related to the expected sales of his/her product and his/her product sales forecasts. Thus, if the share of all the retail market sales is used for this purpose, the breakdown approach shows that the capital accounts for 6,95 per cent of the company's sales. The number/size of the population can also be a factor. In this case, the producer expects 7,39 per cent of his/her sales to be in the capital. Product sales forecasting may take into account component factors, such as the factor of buying power, which can be calculated according to several coefficients. For example, the coefficients $0,2,0,5$ and 0,3 can be respectively assigned to the number/size of the population, its income, and the volume of retail trade [19]. When provided historical data is available, the factors which are purposeful to relate to sales forecasting for the products of a specific company and the weights of these factors can be determined with the help of the correlation and regression methods. 
Table 1. Data on the company's activity planning as used by production managers

\begin{tabular}{|c|c|c|c|}
\hline $\begin{array}{l}\text { Type of } \\
\text { data }\end{array}$ & Planning steps & Data used for planning & $\begin{array}{c}\text { Frequency of use, } \\
\text { per cent }\end{array}$ \\
\hline \multirow[t]{3}{*}{$\begin{array}{l}\text { Principal } \\
\text { forecasting } \\
\text { data }\end{array}$} & Sales forecasts & $\begin{array}{l}\text { - The company's own products sales } \\
\text { forecasting } 3 \text { years in advance } \\
\text { - Branch performance forecasting } 3 \text { years } \\
\text { in advance } \\
\text { - The company's own products sales } \\
\text { forecasting according to segments } \\
\text { - Branch performance forecasting } \\
\text { according to segments }\end{array}$ & $\begin{array}{l}72 \\
59 \\
39 \\
22\end{array}$ \\
\hline & $\begin{array}{l}\text { Market share } \\
\text { forecasts }\end{array}$ & $\begin{array}{l}\text { - Determination of the share of the } \\
\text { company's own products } 3 \text { years in } \\
\text { advance } \\
\text { - Determination of the share of the } \\
\text { company's own products according to } \\
\text { segments } \\
\text { - Determination of the share of competing } \\
\text { products } 3 \text { years in advance } \\
\text { - Determination of the share of competing } \\
\text { products according to segments }\end{array}$ & $\begin{array}{l}44 \\
34 \\
30\end{array}$ \\
\hline & $\begin{array}{l}\text { A product's } \\
\text { income } \\
\text { forecasting }\end{array}$ & $\begin{array}{l}\text { - Computation of the products' direct } \\
\text { expense } \\
\text { - Estimation of a product's direct income } \\
\text { - Computation of the products' relative } \\
\text { share according to segments }\end{array}$ & $\begin{array}{l}71 \\
70 \\
17\end{array}$ \\
\hline \multirow[t]{2}{*}{$\begin{array}{l}\text { Strategic } \\
\text { analysis } \\
\text { data }\end{array}$} & $\begin{array}{l}\text { Relative market } \\
\text { share } \\
\text { forecasting }\end{array}$ & $\begin{array}{l}\text { - Absolute market share expressed as a } \\
\text { percentage, which in this case is the } \\
\text { sales of a company's product divided } \\
\text { by the sales of the leading product } \\
\text { - Estimation of the product's relative share } \\
3 \text { years in advance } \\
\text { - Computation of the product's relative } \\
\text { share according to segments }\end{array}$ & $\begin{array}{l}49 \\
38 \\
33\end{array}$ \\
\hline & $\begin{array}{l}\text { Value of market } \\
\text { share } \\
\text { forecasting }\end{array}$ & $\begin{array}{l}\text { - Value of the market share } \\
\text { - Determination of the product's relative } \\
\text { share, } 3 \text { years in advance } \\
\text { - Computation of the product's market } \\
\text { share according to segments }\end{array}$ & $\begin{array}{l}28 \\
15 \\
11\end{array}$ \\
\hline $\begin{array}{l}\text { Financial } \\
\text { data }\end{array}$ & $\begin{array}{l}\text { Profit and } \\
\text { financial } \\
\text { forecasts }\end{array}$ & $\begin{array}{l}\text { - The product's profitability, } 3 \text { and more } \\
\text { years in advance } \\
\text { - Current value of alternative income } \\
\text { flows of the market share }\end{array}$ & $\begin{array}{l}52 \\
25\end{array}$ \\
\hline
\end{tabular}

The essence of the "bottom-up" method is the following: the sales forecasts for each individual element are combined to develop a general forecast. The method is most widely used when such homogeneous items as products, product lines or market segments are forecasted. Thus, in order to forecast transportation volumes, it is purposeful for a transport company to apply the "bottom-up" method by relating 3 general types of services, namely, 1) The current project in accordance with the agreements already in force. Its success can be forecasted in a relatively accurate way; 2) A certain project that can be derived from the current project; and 3) New projects, which are determined by the company's 
market offers and are difficult to predict. Each of these forecasts is the sum of a large number of individual products or projects. The forecasts for each type of the 3 transportation orders can be summed up, in order to obtain a general forecast of the transportation volumes for the whole company.

As a rule, forecasting is primarily carried out on the basis of past sales tendencies, as the principal dependencies and tendencies are expected to repeat themselves in the future. This does not always prove correct. However, such a forecast is valuable as the departure point for the planning process, which provides the initial objective data and stimulates the study of factors that influence the company's sales. In this respect, quantitative techniques are widely used. Subjective methods, such as surveys and team work, are also used for the purposes of forecasting, because the evaluation provided by experienced professionals with a well-developed intuition frequently turns out to be more accurate than the mathematical processing of historical data.

Forecasting employs several methods, which can be classified according to a number of characteristic features.

1. According to the forecasted period, all forecasts are divided into short-term (up to 1 year), medium-term (1-3 years), and long-term (3-10 years) forecasts.

2. According to the object of forecasting, all forecasts are subdivided into general and partial forecasts. A general forecast is developed in order to evaluate the future economic development, while a partial forecast includes only a part of the economic activity. For example, when a sales forecast is prepared.

3. A widely applied classification of forecasting methods is their subdivision into qualitative (intuitive) and quantitative (systematic) forecasting methods. The opinions of different people, such as consumers, experts, chief executives, etc, are of crucial importance in intuitive methods. These methods are used especially when a given problem cannot be expressed quantitatively, or when the available data is insufficient for a quantitative evaluation, or when it is required to develop a forecast that would complement the quantitative forecast. Quantitative forecasting methods express, by means of a mathematical formula, the relationship between forecasted variables and other variables, which can be earlier values or other variables relating to the already mentioned variables.
The following forecasting methods are applied especially frequently $[2,5,6-13]$ :

1. Trend extrapolation and smoothing methods (the method of moving averages, exponential smoothing)

These methods are based on the tendencies of the development of a situation in the past, which are then extrapolated into the future. An assumption is made that the regularities that manifested them in the past will continue in the future. Such an assumption is more dangerous because the more dynamic the market development, the longer the period of time for which the forecast is formulated. These methods may be popular, because they are simple in application. Thus, the forecast developed by means of using the mentioned techniques does not require any additional expenditure, except for the computation cost. Nevertheless, alongside statistical methods, sales forecasting also has to take into consideration qualitative evaluations describing the company's turnover, the position in the market, and the market's share.

\section{Regression analysis}

According to this method, the values of related variables are established and forecasted on the basis of one or several values of independent variables. For example, a simple regression analysis is used if it is necessary to establish a relationship between the turnover of a product and the expenditure on advertising, while a multiple regression analysis is employed when it is required to establish a relationship between the product's turnover and the number of retail businesses, expenditure on advertising, and sales promotion. Independent variables are often the price, revenue, promotion cost, and the number/size of the population.

\section{Sales force composites}

Practice shows that a great importance is also attached to the subjective evaluation by the sale's staff, because their market expertise should help them to forecast the future development of the market in a particularly accurate way. The strong side of this method is that the market is close at hand and influences the actual evaluation of the business's environment, because even short-lasting changes are taken into consideration. On the other hand, there is a danger that salespeople will underestimate the forecasted demand for fear of overestimating the sales' volumes. In order to improve the quality of forecasts, a company may help its sale's staff, that is, encourage them. For example, the staff can be supplied with a comparative analysis of previous forecasts and with the volumes of actual 
sales, some data on the company's prospects, the behaviour of its competitors, and marketing schemes. There are many advantages in the participation of salespeople in forecasting. The sales staff who are well acquainted with the tendencies of the sale's development and take an active part in the forecasting process, then feel very confident about the set sale's quotas and seek to achieve the set goals.

\section{Juries of executive opinion}

The upper-level managers of a company or its sale's office make decisions on the basis of the available information. They are only able to outline the principal directions of the development, because there is a danger that the data is inaccurate and does not reflect the actual situation in the market. On the other hand, such evaluations are obtained quickly and at a low cost and may be the basis of a final forecast. Moreover, it is possible to compare the judgement by chief executives and the forecasts carried out by means of using other methods. As the top management people are in the position to set prices, to establish priorities, and to decide the fate of the organisation, the method under consideration here should necessarily be used.

\section{Consumer surveys}

A consumer survey frequently provides the most reliable data. In order to reduce costs and labour intensity, the method of the "random selection" of potential consumers is applied most often. Such a forecast is more accurate if the method makes use of a probability scale rather than the consumer's answers about their intentions to buy or not to buy a specific product. While the polling technique is certainly of great importance here, the evaluation of economic, psychological, and other factors that characterise consumers are no less significant. However, consumer surveys are applicable only for the purposes of shortterm forecasting; otherwise, the representation of a forecast decreases.

\section{The Delphi method}

Sales determinations frequently make use of assessments by experts, which have a variety of modifications. Sales forecasts often employ modifications that are similar to the Delphi method.

Under this method, the typical procedure is as follows $[6,8,16,17]$

- reparation for a survey

- An expert's survey is carried out

- Tabulation of the results of the expert's survey

- Tabulated results are returned to the experts

- Repetition of the survey
At the initial stage, two main tasks may be singled out, namely, the formation of a panel of experts and the development of questionnaires.

The formation of a group of experts faces the following two principal questions: Who should be considered an expert and how many of them should be included in the group? When selecting experts, two criteria, namely, competence and motivation, should be taken into consideration. Competence is clearly an inseparable attribute of any expert. However, unless motivated, the expert may submit his/her judgement indifferently and irresponsibly. Therefore, a specialist with a medium level of competence, but motivated in the survey should be preferred to a highly competent, though indifferent, one. There are a variety of formal methods with the help of which candidates can be assessed, although these methods may only serve as a complementary means rather than a single assessment criterion, because of the subjectivity of the determination of their parameters.

The number of the experts who take part in a demand survey depends on the number of potential candidates, the scale of the survey and its timing, and the available funds. A variety of techniques may be applied in order to determine the number of experts, although it is possible to employ the characteristic features of the mentioned methods and only provided expert evaluations are then available. Therefore, formal methods should only be used to verify whether there are enough experts in a group or not.

When responses from the panel have been collected and generalised, a relatively reliable and frequently, the only possible information about a specific product's demand is then obtained. Relating, on the one hand, experience, intuition, and expertise and, on the other, the available data may help to prepare a more accurate forecast.

When applying the method of the jury of expert's opinions, the problem is how to generalise individual evaluations so that group assessments are as accurate as possible. Practice shows that group evaluations are more reliable than individual ones. The number of experts should be large enough for the opinion of a single specialist not to have an unfair and larger weight. On the other hand, an expert poll cannot be a mass activity, because in such a case the competence of the experts is lower, which in its turn reduces the accuracy of group evaluations. It is possible to improve the accuracy of group assessments in two ways: either by preparing and implementing a set of the means that would help to obtain as accurate as possible evaluations by the experts or to make use of 
the methods for the processing of individual evaluations.

In the first case, to ensure the competence of the specialists taking part in the survey is of crucial importance. The quantitative evaluation of the competence of a particular expert may be used as the weight coefficient of his/her judgement, which will be taken into consideration when preparing a group assessment. The weight of the expert's opinion is often expressed by means of a 10-point scale. There are two ways of assessing the experts' competence. One of them is a self-assessment. The "grade" which an expert has given himself/herself is subsequently divided by the highest possible mark, i.e. 10, thus resulting in a weight coefficient, which is multiplied by the expert's forecast. This method is convenient to apply, because the weight of the expert's forecast is obtained without the preliminary processing of the data. The other technique makes use of the assessment of the whole group by a particular member of such a group. However, the competence of the experts in this case has to be assessed before the survey is completed.

To sum up, an accurate sales forecast requires the application of a number of different quantitative methods as well as qualitative or subjective evaluations by upper level managers, consumers, and other experts.

A summary of the descriptions of forecasting methods as presented in $[3,4,10,11,13,14,15,18-20]$ and allows one to determine the strengths and weaknesses of each technique. The principal advantages and limitations of the forecasting methods under discussion here are presented in Table 2.

The survey conducted in 334 German companies with the purpose of finding out what forecasting methods are used and how frequently they are applied as well as how the reliability of specific forecasting methods is evaluated has shown [14] that the companies apply the following methods most often: trend extrapolation, the method of moving averages, regression analysis, jury of executive opinion, interviews of salespeople, consumer surveys, and analogy method. A large number of the companies under discussion make use of subjective evaluations by sales specialists $(87,7$ per cent), juries of executive opinion (85,9 per cent), and consumer surveys ( 81,8 per cent). More than 50 per cent of these companies apply the following statistical forecasting methods: trend extrapolation $(73,7$ per cent) and the method of moving averages $(67,7$ per cent). The most reliable techniques are considered to be regression analysis, jury of executive opinion, and analogy method.
When selecting a specific forecasting technique to be applied in a particular situation, one has to take into consideration a considerable number of factors. The most significant ones are cost and accuracy. How much money is budgeted for developing the forecast? What are the possible costs of error and what are the possible benefits that may result from an accurate forecast? The higher the accuracy, the bigger the cost and so, it is of great importance to carefully weigh the cost-accuracy relationship. The best forecast is not necessarily the most accurate or the least costly. There are several combinations of accuracy and cost that are deemed best by management.

With respect to the computation of forecasting accuracy, all the forecasting techniques can be subdivided into smoothing techniques and the methods that are based on the principle of least squares, such as regression analysis and trend extrapolation.

The computation of forecasting accuracy by means of smoothing techniques frequently makes use of the following errors and deviations in order to evaluate the quality of the forecast under discussion [6-9, 13]:

Mean Square Error:

$$
M S E=\frac{\sum\left(F_{t}-Y_{t}\right)^{2}}{n} ;
$$

The Mean Absolute Deviation:

$$
M A D=\frac{\sum\left|F_{t}-Y_{t}\right|}{n}
$$

Mean Forecast Error:

$$
M F E=\frac{\sum\left(F_{t}-Y_{t}\right)}{n} ;
$$

The Mean Absolute Percentage Error:

$$
M A P E=\frac{1}{n} \sum\left|\frac{F_{t}-Y_{t}}{Y_{t}}\right| .
$$

The estimation of these errors helps to select such parameters for smoothing techniques as the smoothing constant $\langle$ and to compare the results obtained with the help of a variety of forecasting methods.

The coefficient analogous to the coefficient of variation may be employed to arrive at the percentage estimate of the accuracy of a forecast:

$$
\frac{\sqrt{M S E}}{F_{t}} \cdot 100 \% \text {. }
$$


Table 2. Advantages and disadvantages of forecasting methods

\begin{tabular}{l|l}
\hline \multicolumn{1}{c|}{ Method } & \multicolumn{1}{c}{ Advantages } \\
\hline $\begin{array}{l}\text { Qualitative methods } \\
\text { Juries of executive } \\
\text { opinion }\end{array}$ & $\begin{array}{l}\text { Such evaluations may be obtained quickly and } \\
\text { at a low cost. They may either be the basis for } \\
\text { a final forecast or may be compared with the } \\
\text { forecasts made with the help of other methods. } \\
\text { The technique is an effective one when applied } \\
\text { as a complementary method. }\end{array}$
\end{tabular}

(n)

Forecasting based on consumer surveys
Consumer questioning provides reliable data. The accuracy of a forecast increases when it makes use of a probability scale rather than consumers' answers about their intentions to buy or not to buy a specific product. Consumer polls supply a company with information about the intentions to buy a product, level of consumption, buying periods, and reasons for buying. With respect to industrial goods, a poll is successful when there are several customers who are able and willing to predict their future behaviour. Such surveys provide the data that cannot be obtained in any other way.
The Delphi method

Sales force composites
The responses of experts are anonymous, which encourages them to be open. This method is a convenient one for people who cannot meet in one particular place. At each stage a new questionnaire is prepared on the basis of the data obtained at an earlier stage, which increases the volume of the data on which the participants can base their opinion. Such a systematic taking into account of an expert's opinion may be applied to solve almost any problem, no matter what products serve as the basis for the forecast.

By making use of their market expertise, salespeople should develop quite a successful forecast, because their closeness to the market helps them to take into consideration even shortterm changes. The interviews of the sales staff offer an opportunity to generalise specific tendencies, to determine the advantages and limitations a company's products and services, competitors' strategy, characteristic features of the mass consumer, and to prepare a sales forecast on the basis of different product categories, consumer groups, and regions. Salespeople are in direct contact with consumers and most probably know their likes and dislikes. Quite often they also know about their future plans and expectations.
Limitations

The chief executives of a company or the staff of its sales office can only determine general tendencies, because there is a danger to arrive at a forecast not reflecting actual situation. This method relies too heavily on a subjective judgement. The results of a forecast are influenced by the opinion of a top-ranking executive $(-s)$, whose judgement forms the basis for other evaluations. Therefore, there is a risk that the opinion of a single person will be dominant.

In the consumption market, the method is suitable only when a short-term forecast is prepared. Otherwise, the representation of the forecast is reduced. Sometimes consumers do not answer the company's questions, and their actual behaviour differs from their intentions. In many cases, the number of consumers is too large or it is impossible to identify potential customers. For a survey to be successful the method requires considerable experience, it is necessary to properly prepare the question-naires, conduct the survey, and evaluate the results.

The problem of conservative tendencies is of considerable significance here. To predict technological changes is quite complicated. If an expert is not motivated to conduct a survey, he/she may present his/her evaluation indifferently and irresponsibly. It is possible to arrive at a misleading conclusion. This method is less reliable than consumer surveys.

There is a risk that sales representatives will underestimate the demand for the fear of overestimating the sales volumes. According to $\mathrm{Mr}$ F. Kotler, judgement by a member of the sales staff may be influenced by his/her personality (pessimist, optimist) and his/her success or failure at work. Moreover, they are not always able to make a judgement about the tendencies of the economic development of the country they work in. Thus, the sales staff may incorrectly interpret consumer's needs and may be unable to distinguish between what consumers would like to do and what they actually will do. Furthermore, sales representatives may not have enough time to thoroughly prepare a forecast or may consider forecasting completely meaningless. 


\begin{tabular}{|c|c|c|}
\hline Method & Advantages & Limitations \\
\hline $\begin{array}{l}\text { Quantitative methods } \\
\text { Trend extrapolation }\end{array}$ & $\begin{array}{l}\text { The method is uncomplicated in application, } \\
\text { because it does not require any additional } \\
\text { expenditure except for computation cost. }\end{array}$ & $\begin{array}{l}\text { One presumes that the regularities that manifested } \\
\text { them in the past will continue in the future. } \\
\text { However, such an assumption is risky, especially } \\
\text { when the market is developing dynamically or } \\
\text { when the forecast under consideration is a long- } \\
\text { term one. Any further planning, alongside all the } \\
\text { numerical and statistical methods should also take } \\
\text { into account qualitative evaluations. However, the } \\
\text { sales fluctuations that took place in the past, } \\
\text { economic situation, ever-changing consumer } \\
\text { tastes, competition, and degree of market } \\
\text { saturation are ignored. }\end{array}$ \\
\hline $\begin{array}{l}\text { Time series smoothing } \\
\text { (the methods of moving } \\
\text { averages and } \\
\text { exponential smoothing) }\end{array}$ & $\begin{array}{l}\text { The technique is not complicated in application } \\
\text { and helps to prepare a forecast quickly and } \\
\text { easily. The method under discussion is a } \\
\text { forecasting technique that is well understood by } \\
\text { consumers. It is possible to adapt to changing } \\
\text { conditions by means of changing the value of a } \\
\text { smoothing constant and the length of the period, } \\
\text { which is the basis for averaging. }\end{array}$ & $\begin{array}{l}\text { The variables that determine the values of time } \\
\text { series remain unidentified. Past trends will not } \\
\text { necessarily continue in the future. The method } \\
\text { should not be applied when corporate conditions } \\
\text { are unstable and frequently change. The technique } \\
\text { is most suitable when applied to relatively stable } \\
\text { processes or stationary time series. }\end{array}$ \\
\hline $\begin{array}{l}\text { Correlation and } \\
\text { regression analysis }\end{array}$ & $\begin{array}{l}\text { Forecasting on the basis of these methods is } \\
\text { done at a relatively low cost. The techniques } \\
\text { take into consideration the factors that determine } \\
\text { the forecasted value as well as the degree of their } \\
\text { impact. }\end{array}$ & $\begin{array}{l}\text { Independent variables may be interrelated. A } \\
\text { forecast may be misleading if important factors } \\
\text { change during the forecasted period or if new } \\
\text { factors appear. An accurate forecast requires } \\
\text { extensive historical data. The forecasted values are } \\
\text { frequently influenced by the factors whose } \\
\text { quantitative expression is rather complicated. }\end{array}$ \\
\hline
\end{tabular}

The ratio of 10-15 per cent essentially follows the normal distribution, and confidence intervals may be set up.

Correlation and regression analysis (and the respective trend by analogy) help to estimate the accuracy of a forecast on the basis of the following theoretical model:

$$
Y=a_{0}+a_{1} x+\varepsilon,
$$

where $\sum$ is a random value with the average 0 and dispersion $\int^{2}$, while $a_{0}$ and $a_{1}$ are the coefficients whose statistical estimates rest on the principle of least squares.

Firstly, the accuracy of the statistical estimates of the coefficients a0 and a1 is calculated with the help of the Mean Standard Deviation:

$$
s_{a_{1}}=\frac{s_{r e s}}{\sqrt{\sum\left(x_{i}-\bar{x}\right)^{2}}},
$$

$$
s_{a_{0}}=s_{a_{1}} \cdot \sqrt{\frac{\sum x_{i}^{2}}{n}},
$$

where $\mathrm{s}_{\text {res }}$ is a square root from the residual dispersion. Our regression equation may be written in the following way:

$$
\hat{Y}=\bar{Y}+a_{1}(x-\bar{x}),
$$

which means that $Y_{k}$ is the Mean Square Deviation with the given value $\mathrm{x}_{\mathrm{k}}$ :

$$
s_{\hat{Y}_{k}}=s_{\text {res }} \cdot \sqrt{\frac{1}{n}+\frac{\left(x_{k}-\bar{x}\right)^{2}}{\sum\left(x_{i}-\bar{x}\right)^{2}}} .
$$

Therefore, the confidence interval of the regression line, i.e. the average of the forecasted index, is as follows:

$$
\left(\hat{Y}_{k}-t_{\frac{\alpha}{2} ; n-2} \cdot s_{\hat{Y}_{k}} ; \hat{Y}_{k}+t_{\frac{\alpha}{2} ; n-2} \cdot s_{\hat{Y}_{k}}\right)
$$


When $\alpha=0,95$, we get:

$$
\left(\hat{Y}_{k}-2,069 \cdot s_{\hat{Y}_{k}} ; \hat{Y}_{k}+2,069 \cdot s_{\hat{Y}_{k}}\right)
$$

Given the specific fixed value of $x$, it may be possible to arrive at the average $\mathrm{Y}$ by extracting a square root from the Mean Square Deviation of the individual value of $\mathrm{Y}$ :

$$
s_{Y_{\text {ind }}}=s_{\text {res }} \sqrt{1+\frac{1}{n}+\frac{\left(x_{k}-\bar{x}\right)^{2}}{\sum\left(x_{k}-\bar{x}\right)^{2}}} .
$$

One may note that the confidence intervals under discussion are quite wide. Therefore, the question is how to make practical use of the forecasts that are based on these intervals. Forecasting calculations usually rely on several methods, rather than on a single technique. If the results obtained are similar enough, they may be lumped together to arrive at the simple or weighted average of the forecasts. The accuracy of the resulting integrated forecast will depend on the Mean Square Deviation:

$$
s_{\mathrm{int}}=\frac{\sqrt{D_{1}+\ldots+D_{m}}}{m},
$$

where $m$ - the number of the forecasting methods applied.

If the dispersions of the forecast deviation of separate methods are approximately equal, the formula becomes less complicated:

$$
s_{\text {int }}=\frac{s_{m}}{\sqrt{m}},
$$

where $m$ - the number of the forecasting methods employed, and $S m$ - the Mean Standard Deviation of each of the methods. Therefore, the more techniques applied, the smaller the deviation of an integrated forecast. Thus, if $m=5$, the forecast deviation is reduced by 2,24 times.

The following formula helps to calculate the confidence interval of the integrated forecast:

$$
\left(F_{\mathrm{int}}-t_{\frac{\alpha}{2} ; n-2} \cdot s_{\mathrm{int}} ; F_{\mathrm{int}}+t_{\frac{\alpha}{2} ; n-2} \cdot s_{\mathrm{int}}\right)
$$

The factors that influence the choice of forecasting methods include, alongside the cost and accuracy of a forecast, the availability of historical data, the availability of computers, the ability of decision makers to make use of specific techniques, the time needed to collect and analyse data, as well as any prior experience with a technique. The forecast horizon is of considerable significance, because some methods are more suited to short-term forecasts, whereas other techniques work better for long-range forecasting. For example, while the methods of moving averages and exponential smoothing are essentially short-range methods, trend equations can be employed to project over a much longer period of time. Several of the qualitative methods are better suited to long-range forecasts, because they do not require historical data. The Delphi method, juries of executive opinion, and expert surveys are frequently applied in long-term planning. Since new products and services lack historical data, forecasts for these products and services must rely on subjective estimates. Experience with similar items is relevant in many cases.

Sales forecasts have to take into consideration a number of other factors that influence the selection of a forecasting method. The choice of a forecasting technique and its accuracy depend considerably on the novelty of a company's products. The forecasts of the sales of the products and services already on the market require the application of the trend analysis, the market share analysis, the juries of executive opinion, expert surveys, and interviews of salespeople. Provided that neither any radical economic changes, nor changes of competition conditions or consumer needs happen, the sales forecasts should be quite accurate.

Demand forecasting for products or services which, though new to a company, are well-known in their own field should make use of the company's data, judgement by chief executives and a panel of specialists, interviews of sales representatives, consumer surveys, and test marketing. While sales forecasts for the first year should be relatively accurate, they should be much more accurate for later years, because during the first year it is difficult to win the recognition of customers and predict the reaction of competitors.

Demand forecasting for the products or services that are new for the entire branch should rest on consumer polls, test marketing, interviews of sales representatives, and judgement by chief executive officers and experts. Forecasts for the first 2-3 years may be inaccurate, because it is complicated to estimate the rate of consumer recognition. Later forecasts will be more accurate. Even though inaccurate, the initial sales forecast is necessary when seeking to evaluate the scale of growth, compile a budget, distribute resources, monitor the environment and competitors' behaviour, and prepare marketing and production plans. 
The experience of other countries shows that the following forecasting methods are employed most often: qualitative forecasting methods, such as the juries of executive opinion, sales force composites, and the forecasts based on consumer surveys; quantitative forecasting techniques, namely, trend extrapolation and the method of moving averages. Regression analysis, juries of executive opinion, and analogy method are considered to be the most reliable forecasting methods.

Lithuanian businesses may be advised to use relatively simple, reliable, and low-cost forecasting techniques, such as trend extrapolation, time series smoothing, regression analysis, jury of executive opinion, and sales force composites. For the purposes of long-term forecasting it is advisable to apply the Delphi method.

The market conditions force businesses to constantly experience the shortage of data, which is compensated by the results of a forecast. Therefore, properly selected forecasting methods and their adaptation to a company's specific conditions are a highly important strategy of the company's top management people. The skill to determine the company's prospects and to take a reasonable risk on the basis of the entire available data paves the way to success.

\section{Demand Forecasting}

Demand forecasting is a process by which a one-cycle sales forecast is prepared. A year later, when actual sales values of a company's products become known, a new sales forecast is prepared by comparing the actual level of demand with the one forecasted a year ago and determining the differences as well as the possible reasons for their appearance. The cycle of sales forecasting is presented in the Fig.1.

At the initial stage of sales forecasting, a company's products are described, their characteristics are pointed out, the main groups of the products are singled out, and the position of the mentioned groups on the cycle curve is identified.

The company's products have been described and the market in which other manufacturers of the products operate is characterised. Thus, the number of such businesses, their size, the market share which they have been successful in capturing (whether there are any leaders), the quality of the manufactured products, complexity of the market's entrance for new businesses, the type of competition on the market and its intensity are then identified.

The second stage of sales forecasting includes the determination of the sales tendencies that manifested themselves in the past: the trend (whether demand is growing or falling), cyclic fluctuations of demand, length of cyclic periods, the reasons for the cyclic fluctuations in demand, the units of measure for the total product sales (natural or evaluative), whether the products are homogeneous or it is necessary to do an evaluative expression of demand indicators for separate product groups and thereby seek to estimate the level of demand for the company's products.

In order to forecast the future development of demand, it is important to determine the external factors that influenced it in the past and that may continue making a significant impact on the sales level in the future. The sales level may be determined by the factors of the company's economic, social, cultural, political, legal, and technological environment.

It is recommended that a company's upper-level managers and senior company officers from separate departments, suppliers, outside marketing and market research consultants, and the scientists working in the field of management and marketing should participate when determining the factors that influence the sales level. Less suitable in this respect are salespeople's interviews and consumer surveys (especially the surveys of the consumers of consumer products, though those of the consumers of industrial goods may provide extensive valuable data), because such people are not always able to evaluate the goods and are not always able to evaluate the development tendencies of a manufacturer.

The Delphi method can be useful when seeking to identify demand-determining factors. This technique employs as experts, a company's top management and the senior officers of the company's departments, suppliers, outside marketing and market research consultants, and the scientists who work in the sphere of management and marketing. The following stages of the interview of these specialists are recommended:

- Experts point out the factors that influence a company's sales;

- The results are tabulated;

- All the factors which have been identified by the experts as demand-determining are presented, the significance of each of them with respect to the company's sales is evaluated;

- The results having been summed up, one arrives at a list of demand-determining factors with the weight of each factor presented with respect to the sale's level.

Of great importance is not only to identify the factors that make an impact on a company's sales and the degree of their influence, but also to predict their future values. If possible, the factors are expressed 


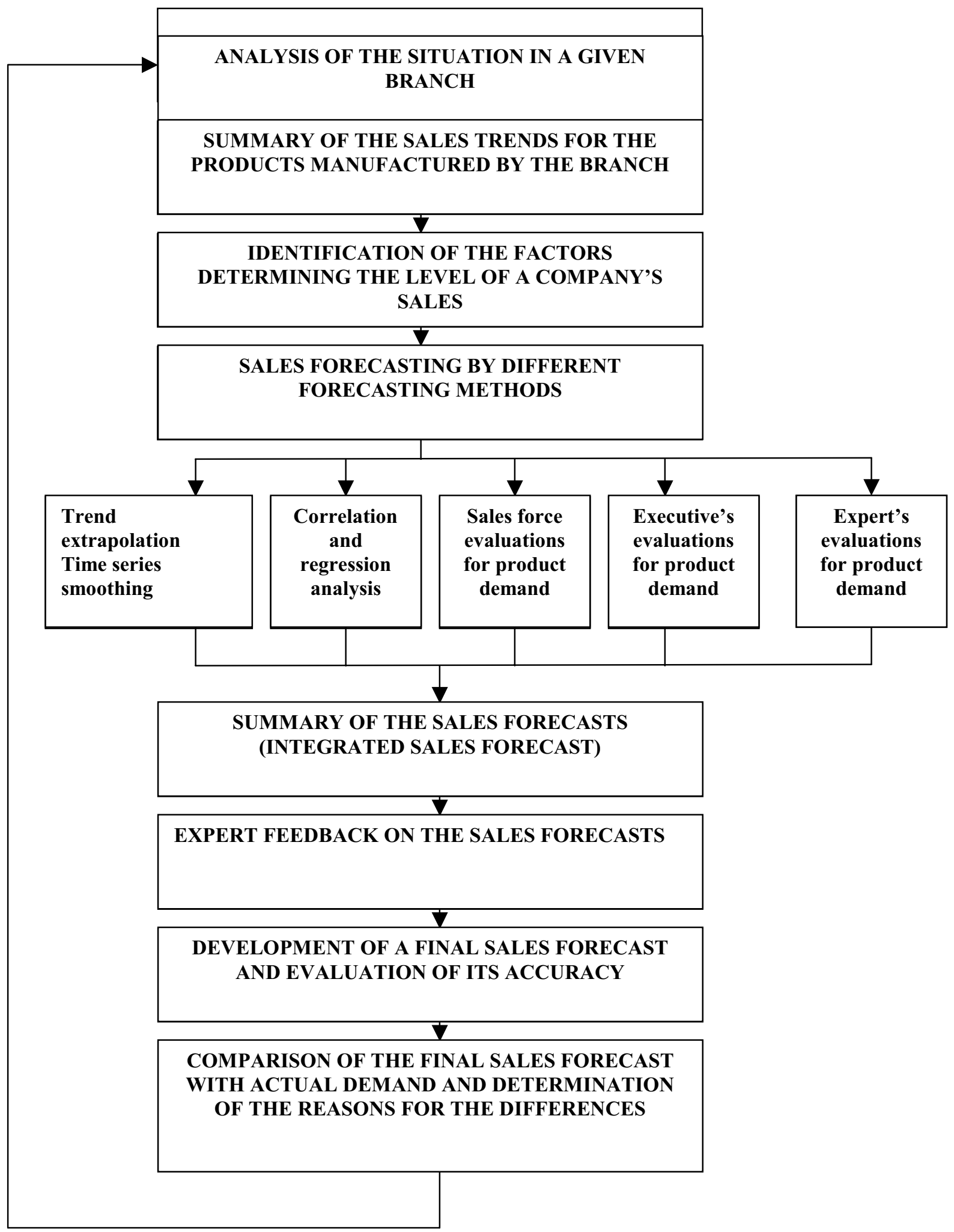

Fig. 1. Cycles of demand forecasting 
quantitatively. Then, the degree of their impact on the product sales may be estimated with the help of analytical methods, such as a correlation analysis.

The analysis of the market situation of a given company is carried out, the data on the sales tendencies of the company's products in the past is generalised, and the factors influencing the sale's level is determined and then a forecast of the company's sales is developed. The forecasting methods recommended for a demand forecast are as follows:

- Quantitative methods: time series smoothing (the methods of moving averages and weighted moving averages, exponential smoothing), trend extrapolation and regression analysis;

- Qualitative methods: juries of executive opinion, expert judgement, and sales' force composites. A forecast based on the results of a consumer survey can be applied when it is required to prepare a sales forecast for durable products or industrial goods.

Even though the application of qualitative forecasting methods is frequently viewed rather sceptically due to the considerable subjectivity of these techniques, they are very useful when a large number of the factors which from the expert's point of view are of crucial importance to the sale's level and cannot be expressed quantitatively or when the available data is of an insufficient basis for a quantitative evaluation. Sales forecasting with the help of qualitative methods is especially important for longer-range marketing planning, because in this case the assumptions which are the basis for sales forecasts, such as the assumption that the influence of the factors that decide the market conditions and the demand for the company's products will not change and so cannot be applied.

The methods best suited for short-term (up to 1 year) sales forecasts are time series smoothing, trend extrapolation, and regression analysis. Such techniques as trend extrapolation, regression analysis, jury of executive opinion, and expert surveys are recommended when developing medium-term (1-3 years) sales forecasts. The juries of executive opinion and especially expert's surveys are of utmost importance to long-range forecasting. It is advisable to include, in a panel of experts, technical specialists who would be able to predict possible radical changes, because a number of technological changes may take place over a long period of time.

The sales forecast having been developed then data on the forecasted demand is presented to the experts. The evaluation of the product's sales is then repeated. A general sales forecast is prepared on the basis of the assumptions made during the forecast, the expertise of the experts, and their knowledge about the market and the company.

The combination of qualitative and quantitative, or objective and subjective, forecasting techniques helps to arrive at an exhaustive description of the future development of demand, which in its turn will help the company to plan its activity in the future and to develop a marketing strategy.

Sales forecasting is a continuous process. At the end of a forecast cycle, the most recent sales data is obtained. It is important to compare the actual demand figures with the forecasted ones and to determine the differences that have manifested themselves as well as the reasons for the appearance of such differences.

Having evaluated economic changes in the country under discussion, changes in demand with respect to a specific company, the sales tendencies which manifested themselves during the forecast period, the appearance of new sales-determining factors, and, finally, the changes of their impact on the sales, management may start a new cycle of sales forecasting, whereby the sales forecast necessary for the company's customers, suppliers, and intermediaries is developed.

\section{Conclusions}

1. The problem of the selection of the appropriate sales forecasting method and the question of the accuracy of different forecasting techniques are topical for Lithuanian business people due to the dynamic nature and the vulnerability of the country's corporate environment and its market processes.

2. The development of the information society in Lithuania creates preconditions for a broad application of quantitative methods of market research, which include different forecasting techniques. However, the complexity of these methods hinders their practical application in small and medium-size enterprises.

3. When selecting forecasting methods for the purposes of their practical application, the factors of utmost importance are the degree of their complexity, costs, and accuracy. The forecasting methods that are recommended for use in Lithuanian corporate practices include trend extrapolation, smoothing techniques, and regression analysis as well as different specialist's interviews that are relatively simple and implemented with the help of standard software (MS Office). Accuracy is ensured by an integrated forecast that is developed on the basis of a number of forecasting 
methods. An integrated forecast is more accurate than any method taken separately.

Continuous sales forecasting helps enterprises to reduce risks linked to the dynamic nature and vulnerability of market conditions.

\section{References}

1. Armstrong M. (1993). A Handbook of Management Techniques. Kogan Page Ltd, London.

2. Bartosevičienè V. (1995). Ekonominè statistika. Kaunas: Technologija. $100 \mathrm{p}$.

3. Berekhoven L. (1996). Marktforschung: metodische Grundlagen und praktische Anwendung.Wiesbaden: Gabler. 446 S.

4. Berkowitz E. N., Kerin R. A., Rudelius W. (1989). Marketing. Irwin. $752 \mathrm{p}$.

5. Boguslauskas V. (1999). Ekonometrija. Kaunas: Technologija. $265 \mathrm{p}$.

6. De Lurgio S. A. Bhame C. D. (1991). Forecasting Systems for Operations Management. New York: Wiley.

7. Dillworth J. B. (1993). Production and Operations Management: Manufacturing and Services. $5^{\text {th }}$ Ed. New York: McGraw Hill.

8. Makridakis S. G., Wheelwright S. C., McGree V. (1983). Forecasting Methods and Applications. $2^{\mathrm{d}}$ Ed. New York: Wiley.
9. Martišius S. (2000). Ekonometrija ir prognozavimas. Vilnius: VU. 127 p.

10. Nieschlag R. (1991). Marketing. Berlin:Durche und Humbolt, $1064 \mathrm{~S}$.

11. Olfert K., Rahn H. J. (1995). Einführung in die Betriebschaftlehre. Ludwidshafen: Kiehl, $536 \mathrm{~S}$.

12. Pranulis V. (1998). Marketingo tyrimai. Vilnius: Kronta. $166 \mathrm{p}$.

13. Stevenson W. J. (1990). Production/Operations Management. Boston: Homewood Irwin. 929 p.

14. Weiss H. Ch. (1995). Marketing. Ludwigshafen: Kiehl. $588 \mathrm{~S}$.

15. Štaras R., Žvinklys J. (1996). Prognozavimo metodai, ju ypatumai ir taikymas. Vilnius: VU. 67 p.

16. Šečkute L. (1993). Ūkio reforma ir ekspertinis prognozavimas. VTU Mokslo darbai. Verslo ekonomika, I. Vilnius: Technika.

17. Šečkutè L. (1997). Prognozès ekonomikos teorijoje. Iš: Tarpt. konferencijos „Verslas ir vadyba'97“ medžiaga. Vilnius: Technika.

18. Vollmann T. E., Berry W. L., Whybark D. C. (1997). Manufacturing Planning and control systems. Irwin, McGraw-Hill. 836 p.

19. Kotler Ph. (1997). Marketing management. Prentice Hall, Inc. 887 p.

20. Evans J. R., Berman B. (1987). Marketing. Macmillan Publishing Company. NY. 351 p. 